\title{
Efeitos da Adição de Inoculantes Microbianos sobre a Composição Bromatológica e Perfil Fermentativo da Silagem de Sorgo Produzida em Silos Experimentais ${ }^{1}$
}

\author{
Paulo Henrique Mazza Rodrigues ${ }^{2}$, Ana Lúcia Senatore ${ }^{3}$, Stefano Juliano Tavares de Andrade ${ }^{2}$, \\ Juliana Martins Ruzante ${ }^{3}$, Carlos de Sousa Lucci ${ }^{2}$, Felix Ribeiro de Lima ${ }^{2}$
}

RESUMO - Foram estudados os efeitos de três inoculantes microbianos, na silagem de sorgo (Agroceres 2005), em 16 silos experimentais, confeccionados a partir de baldes plásticos portando válvulas. O sorgo, cortado aos 97 dias de crescimento (35,9\% de MS), foi homogeneizado e submetido a quatro tratamentos, com quatro repetições: controle, Sil-All (Streptococcus faecium, Pediococcus acidilactici, Lactobacillus plantarum, amilase, hemicelulase e celulase), Silobac (L. plantarum, S. faecium e Lactobacillus sp) e Pioneer 1174 (S. faecium e L. plantarum). Os silos foram abertos após 120 dias para análise da composição bromatológica e perfil fermentativo. Os três inoculantes diminuíram o teor de MS e aumentaram a concentração de etanol e as perdas de MS, em relação ao grupo controle. O Sil-All aumentou o teor de FDN, em relação ao grupo controle, e diminuiu a concentração de amido, em relação ao Silobac, enquanto que o Pioneer 1174 diminuiu a estabilidade aeróbia, em relação ao grupo controle. Não foram observados efeitos sobre os teores de PB, NIDA, carboidratos solúveis, FDA, lignina, hemicelulose, celulose, a digestibilidade in vitro da matéria seca, o poder tampão e as concentrações dos ácidos acético, propiônico, butírico e lático, bem como sobre o pH ou sobre as concentrações de nitrogênio amoniacal.

Palavras-chave: ácidos orgânicos, bactérias láticas, Sorghum bicolor

\section{Effects of Microbial Inoculants on Chemical Composition and Fermentation Characteristics of Sorghum Silage}

\begin{abstract}
Sorghum Agroceres 2005 (35.9\% DM) was ensiled in 16 plastic experimental silos, forming four treatments: control, Sil-All (Streptococcus faecium, Pediococcus acidilactici, Lactobacillus plantarum, amylase, hemicellulase, and cellulase), Silobac ( $L$. plantarum, S. faecium, and Lactobacillus sp), and Pioneer 1174 (S. faecium and L. plantarum). Silos were opened 120 days after ensiling and silage was sampled to proceed chemical analyses. Sil-All, Silobac and Pioneer decreased dry matter content and increased ethylic alcohol concentration and DM losses compared to control. Sil-All increased NDF content compared to control and decreased starch content compared to Silobac, but not as compared to control. Pioneer decreased aerobic stability of silage compared to control. The CP, ADIN, soluble carbohydrates, ADF, lignin, hemicellulose, and celullose contents, in vitro digestibility, buffering capacity, acetic, propionic, butyric and lactic acids, $\mathrm{pH}$ and ammonia concentration did not suffer influence of treatments.
\end{abstract}

Key Words: lactic acid bacteria, organic acids, Sorghum bicolor

\section{Introdução}

O sorgo é uma planta que pode ser comparada ao milho, em relação ao seu valor agronômico e nutritivo. No entanto, em termos de exigências e produção, o sorgo aparece como uma alternativa interessante, uma vez que é mais adaptado à seca, dada a sua capacidade de recuperar-se e produzir grãos após um período de estiagem, produzindo mais matéria seca em áreas de solo menos fértil, quando comparado ao milho. Além disso, como seu sistema radicular se conserva, após a colheita para ensilagem, o sorgo é capaz de rebrotar e produzir até $60 \%$ da matéria seca do primeiro corte (Meeske et al., 1983; Zago, 1991).

O valor nutritivo do sorgo ensilado depende, entre outros, de três fatores principais: do híbrido utilizado, observando altura da planta, produtividade, produção de grãos, tolerância à seca e resistência às doenças; do estádio em que o mesmo foi cortado, que influencia a composição e a qualidade final do material conservado, sendo a fase ideal para a ensilagem entre os estádios pastoso e leitoso (planta já crescida com cerca de $30 \%$ de matéria seca) e dos microrganismos nele presentes durante o processo de ensilagem (Webster, 1962; Cummins, 1971).

$\mathrm{Na}$ silagem de sorgo, a maior porcentagem de

\footnotetext{
1 Projeto financiado pela Fundação de Amparo à Pesquisa do Estado de São Paulo (FAPESP).

2 Professor do Departamento de Nutrição e Produção Animal - FMVZ/USP, Av. Duque de Caxias Norte, 225 - CEP: 13630-000,

Pirassununga - SP. E.mail: pmazza@usp.br

${ }^{3}$ Bolsista de Iniciação Científica (FAPESP).
} 
panículas contribui para o aumento do valor nutritivo e maior porcentagem de matéria seca do material ensilado. É sabido que o amido se concentra nos grãos e o açúcar, nos colmos, sendo que teores de açúcar de 6 a $8 \%$ são suficientes para uma boa fermentação bacteriana. No entanto, modificações no processo fermentativo do sorgo podem comprometer o valor nutritivo do material, já que a produção da "água de metabolismo" reduz o teor de MS, e a diminuição dos carboidratos solúveis e o aumento proporcional de FDN diminuem a digestibilidade da MS, oque limita o aproveitamento da silagem (Zago, 1991).

Os vários aditivos existentes no mercado vêm sendo estudados mais recentemente por meio dos resultados obtidos na preservação e fermentação da silagem, além das respostas no desempenho animal. Os aditivos que encontram-se à disposição do produtor podem ser classificados como inibidores ou estimulantes da fermentação. Os mais utilizados são os estimulantes microbianos da fermentação, mas também são bastante comuns, em outros países, os ácidos (propiônico e fórmico), fontes de nitrogênio não protéico (amônia e uréia) e enzimas (Harrison et al., 1994).

De maneira geral, tais aditivos deveriam ter capacidade comprovada para redução de perdas de matéria seca, aumento da qualidade higiênica, limitação de fermentações secundárias, aumento da estabilidade aeróbia e do valor nutritivo (Henderson, 1993). No entanto, os efeitos do uso de aditivos, seja sobre a fermentação, composição da silagem ou desempenho animal, estão condicionados ao tipo de inoculante e sua atividade biológica, à quantidade aplicada e ao tipo de forragem, em teor de matéria seca e composição química (Harrison et al., 1994). Assim, por exemplo, culturas de bactérias produtoras de ácido lático têm efeitos sobre a velocidade de redução e manutenção do $\mathrm{pH}$, o que permite a preservação do material ensilado, minimiza perdas de nutrientes e inibe o crescimento de clostrídios. Já o emprego de celulase, hemicelulase e amilase, por meio da quebra dos polissacarídeos da parede celular e do amido dos grãos, aumenta a disponibilidade de açúcares para a fermentação pelos lactobacilos, o que melhora a utilização animal das silagens (Whittenburry et al., 1967; Cleale et al., 1990; Chen et al., 1994).

Considerando que, durante a abertura, um silo é exposto à deterioração aeróbia, processo caracterizado por aumentos de temperatura, pH e oxidação dos produtos da fermentação, os inoculantes microbianos surgem como alternativa para evitar perdas elevadas. Assim, Meeske et al. (1983), em experimento utilizando dois tipos de inoculantes, um contendo Lactobacillus plantarum, Streptococcus faecium e Pediococcus acidilactici, e outro contendo essas três bactérias láticas e enzimas como celulase, hemicelulase e amilase, em sorgo ensilado em dois estádios, final de florescimento e pastoso, constataram uma rápida produção de ácido lático e redução no pH das silagens tratadas, quando comparadas aos controles. No entanto, não observaram efeitos positivos na prevenção da deterioração. Além disso, manchas de bolor foram encontradas, após exposição ao ar, somente nas silagens com inoculantes e enzimas, e em maior quantidade no sorgo ensilado em estádio pastoso. Sanderson (1993) obteve resultados semelhantes, testando uma mistura de Lactobacillus plantarum e Streptococcus faecium, em uma silagem de sorgo colhido em estádio pastoso, com $29 \%$ de matéria seca quando ensilado.

Culturas de Lactobacillus plantarum e Lactobacillus acidophilus também foram testadas como aditivos na silagem de sorgo, sendo que a recuperação de nutrientes, o perfil de fermentação (concentração de ácidos orgânicos) e o pH não foram influenciados pela adição destes inoculantes (Ely et al., 1981).

Objetivo-se, com o presente trabalho, estudar o efeito da adição dos inoculantes microbianos disponíveis no mercado brasileiro sobre a composição bromatológica e o perfil fermentativo da silagem de sorgo.

\section{Material e Métodos}

O trabalho foi conduzido nas dependências do Departamento de Nutrição e Produção Animal da Faculdade de Medicina Veterinária e Zootecnia da Universidade de São Paulo (Campus de Pirassununga).

O sorgo (Agroceres 2005) foi cortado aos 97 dias de crescimento $(35,86 \%$ de MS). Após colhido manualmente e picado por meio de picadeira, em fragmentos de tamanho médio de $2,0 \mathrm{~cm}$, o material original foi amostrado em diferentes pontos para posteriores análises bromatológicas, segundo metodologias expostas adiante. Após homogenização, foram pesadas alíquotas do material para colocação em 16 silos experimentais, confeccionados a partir de baldes plásticos com $252 \mathrm{~mm}$ de altura e $245 \mathrm{~mm}$ de diâmetro e com tampas superiores portando válvulas do tipo "bunsen", para o livre escape dos gases. Os silos foram divididos em quatro tratamentos, um controle e

R. Bras. Zootec., v.31, n.6, p.2373-2379, 2002 
três com adição de inoculantes comerciais, segundo as recomendações de cada fabricante, em delineamento inteiramente casualizado, com quatro repetições para cada tratamento. Foram utilizados como inoculantes os produtos comerciais Sil-All (Alltech do Brasil Agroindustrial Ltda.), Silobac (Biotecnal) e Pioneer 1174 (Pioneer Sementes Ltda.).

Os inoculantes aplicados foram:

a) Sil-All: produto à base de Streptococcus faecium, Pediococcus acidilactici e Lactobacillus plantarum, bem como, amilase, hemicelulase e celulase, na dose de $10 \mathrm{mg}$ por $\mathrm{kg}$ de forragem; o produto possui $8,0 \times 10^{10}$ unidades formadoras de colônia/g.

b) SiloBac: produto à base de L. plantarum, $S$. faecium e Lactobacillus sp., na dose de 2,0 mg por $\mathrm{kg}$ de forragem; o produto possui $5,26 \times 10^{10}$ unidades formadoras de colônia/g.

c) Pioneer 1174: produto à base de S. faecium e L. plantarum, na dose de $1,11 \mathrm{mg}$ por $\mathrm{kg}$ de forragem; o produto possui $9,0 \times 10^{10}$ unidades formadoras de colônia/g.

Aproximadamente $6 \mathrm{~kg}$ de massa úmida foram colocados em cada silo e compactados, sendo os silos fechados com as tampas valvuladas e, então, pesados. A compactação correspondeu a aproximadamente $500 \mathrm{~kg}$ de silagem $/ \mathrm{m}^{3}$, sendo os silos mantidos por 120 dias em local abrigado.

Antes da abertura, os silos foram pesados para posterior determinação das perdas de matéria seca. Uma vez abertos, as massas retiradas de cada silo foram homogenizadas, sendo uma parcela separada para determinação de matéria seca, em estufa de ar forçado, proteína bruta (AOAC, 1980), componentes da parede celular (FDN, FDA e lignina, segundo Van Soest, 1967), carboidratos solúveis (Johnson et al., 1966), amido (Pereira \& Rossi, 1995), nitrogênio insolúvel em detergente ácido (Van Soest \& Robertson, 1985), poder tampão (Tosi, 1973) e digestibilidade in vitro da matéria seca (Tilley \& Terry, 1963). Para a análise de FDN foi omitido o sulfito de sódio, mas adicionada a a-amilase. Outra fração foi colocada em prensa manual para extração dos sucos e imediata determinação do $\mathrm{pH}$ (medição em potenciômetro) e do nitrogênio amoniacal (Foldager, 1977). Parte do suco foi fixada e congelada para posterior determinação dos ácidos orgânicos por cromatografia gasosa (Erwin et al., 1961).

Os cálculos das perdas por fermentação foram realizados através da diferença entre os pesos das massas obtidos ao enchimento e abertura dos silos, multiplicados pelos respectivos teores de matéria seca. Finalmente as perdas foram transformadas em porcentagem da massa inicial.

Para determinação da estabilidade aeróbia da silagem, aproximadamente $2,0 \mathrm{~kg}$ de massa úmida foram retirados de cada balde, transferidos para caixas de isopor, com capacidade de 5 litros, e armazenadas em local coberto e à temperatura ambiente, a fim de permitir tomadas de temperatura ambiental e da silagem às $0,12,24,48,72,96$ e 120 horas após a abertura dos silos, por meio de um termômetro inserido $10 \mathrm{~cm}$ dentro da massa contida na caixa de isopor. A estabilidade aeróbia foi calculada como uma taxa de elevação de temperatura, usando o máximo da temperatura observada dividida pelo tempo necessário para alcançar a máxima temperatura (Ruppel et al., 1995). Adicionalmente foram avaliados a máxima temperatura alcançada $\left({ }^{\circ} \mathrm{C}\right)$ e o tempo para a obtenção da máxima temperatura (em horas).

As diversas variáveis foram submetidas à análise de variância pelo procedimento GLM do Statistical Analysis System (SAS, 1985), sendo as médias comparadas pelo teste Tukey. Para todas as análises realizadas, foi utilizado um nível de significância de 5\%.

\section{Resultados e Discussão}

Os dados de composição bromatológica do material utilizado para a confecção das silagens, bem como a composição das silagens submetidas aos quatro tratamentos, encontram-se na Tabela 1. A adição dos inoculantes à silagem diminuiu a matéria seca total em 7,1\% (2,4 unidades percentuais), 6,8\% (2,3 unidades percentuais) e $12,4 \%$ (4,2 unidades percentuais) para os produtos Sil-All, Silobac e Pioneer, respectivamente, em relação ao grupo controle. Esse efeito não poderia ser explicado simplesmente pela adição de água para diluição e homogeneização dos inóculos, uma vez que o grupo controle também recebeu proporcional adição de água (placebo). Tal efeito parece justificar a afirmação de Zago (1991) que as modificações no processo fermentativo do sorgo poderiam reduzir o teor de MS, devido à produção da "água de metabolismo", e, conseqüentemente, aumentar a porcentagem de FDN e diminuir a digestibilidade da MS. Também é possível que compostos voláteis, como o etanol e outros, produzidos em maiores quantidades nessas silagens (Tabela 2), tenham sido perdidos durante a avaliação

R. Bras. Zootec., v.31, n.6, p.2373-2379, 2002 
da matéria seca, subestimando tais valores. Aumentos de 9,01; 9,11 e 14,52 unidades percentuais de perdas de matéria seca, causados pelos inoculantes Sil-All, Silobac e Pioneer, respectivamente, em relação ao grupo controle, encontrados neste experimento (Tabela 3), parecem também ser explicados por esses fenômenos. O valor negativo de perda de matéria seca encontrado para o grupo controle não diferiu de zero pelo teste $\mathrm{t}$, para média igual a zero $(\mathrm{P}=0,8087)$.

No presente experimento, apenas o produto comercial Sil-All diferiu $(\mathrm{P}<0,05)$ do grupo controle quanto ao teor de FDN, aumentando seu valor em 4,5\% (2,6 unidades percentuais). Embora a análise de variância tenha apresentado resultado significativo para a digestibilidade in vitro da matéria seca
$(\mathrm{P}=0,0400)$, não foi possível separar os efeitos de tratamento pelo teste de Tukey. Nenhum dos tratamentos alterou os teores de FDA, lignina, carboidratos solúveis, proteína bruta, nitrogênio insolúvel em detergente ácido ou poder tampão.

Os produtos Sil-All e Silobac diferiram quanto ao teor de amido da silagem. O primeiro diminuiu o teor desse tipo de carboidrato em 22,7\% (4,4 unidades percentuais), quando comparado com o segundo. Embora não diferisse do grupo controle, a tendência do produto comercial Sil-All em diminuir o teor de amido é justificada pela presença de amilases neste inoculante. Entretanto, não foram observados efeitos sobre os teores de hemicelulose e celulose da silagem tratada com Sil-All, apesar desse produto também conter hemicelulases e celulases.

Tabela 1 - Composição bromatológica do sorgo e de suas silagens submetidas à aplicação de inoculantes Table 1 - Chemical composition of sorghum and inoculated silages

\begin{tabular}{|c|c|c|c|c|c|c|c|c|}
\hline & \multirow[t]{2}{*}{$\begin{array}{l}\text { Planta de sorgo } \\
\text { Sorghum crop }\end{array}$} & \multicolumn{4}{|c|}{$\begin{array}{c}\text { Tratamento }^{2} \\
\text { Treatment }\end{array}$} & \multirow[t]{2}{*}{$\begin{array}{l}\text { Média } \\
\text { Mean }\end{array}$} & \multirow[t]{2}{*}{$\mathrm{CV}$} & \multirow[t]{2}{*}{ Prob. } \\
\hline & & $\begin{array}{c}\text { Controle } \\
\text { Control }\end{array}$ & $\begin{array}{c}\text { Sil-All } \\
\text { Sil-All } \\
\end{array}$ & $\begin{array}{l}\text { Silobac } \\
\text { Silobac }\end{array}$ & $\begin{array}{l}\text { Pioneer } \\
\text { Pioneer }\end{array}$ & & & \\
\hline $\begin{array}{l}\mathrm{MS}^{1} \\
D M\end{array}$ & 35,86 & $33,85^{\mathrm{a}}$ & $31,43^{b}$ & $31,57^{b}$ & $29,63^{c}$ & 31,62 & 5,05 & 0,0001 \\
\hline $\begin{array}{l}\mathrm{PB} \\
C P\end{array}$ & 13,02 & 13,28 & 14,08 & 13,81 & 13,95 & 13,79 & 9,36 & NS \\
\hline $\begin{array}{l}\text { NIDA } \\
A D I N\end{array}$ & 24,82 & 28,97 & 27,83 & 27,57 & 28,63 & 28,25 & 10,30 & NS \\
\hline $\begin{array}{l}\text { FDN } \\
N D F\end{array}$ & 64,62 & $58,14^{\mathrm{bc}}$ & $60,75^{\mathrm{a}}$ & $57,41^{\mathrm{c}}$ & $59,34^{\mathrm{ab}}$ & 58,79 & 2,45 & 0,0011 \\
\hline $\begin{array}{l}\text { FDA } \\
A D F\end{array}$ & 39,30 & 36,33 & 37,30 & 35,51 & 38,37 & 36,88 & 4,63 & NS \\
\hline $\begin{array}{l}\mathrm{Lig} \\
\mathrm{Lig}\end{array}$ & 9,72 & 8,34 & 8,48 & 8,77 & 9,32 & 8,73 & 15,21 & NS \\
\hline $\begin{array}{l}\text { Hemi } \\
\text { Hemi }\end{array}$ & 25,32 & 21,81 & 22,20 & 21,90 & 20,97 & 21,72 & 7,31 & NS \\
\hline $\begin{array}{l}\text { Cel } \\
\text { Cell }\end{array}$ & 29,58 & 27,99 & 28,82 & 26,76 & 29,04 & 28,15 & 8,86 & NS \\
\hline $\begin{array}{l}\text { Amido } \\
\text { Starch }\end{array}$ & 16,45 & $17,71^{\mathrm{ab}}$ & $14,90^{\mathrm{b}}$ & $19,27^{\mathrm{a}}$ & $16,20^{a b}$ & 17,02 & 13,89 & 0,0305 \\
\hline $\begin{array}{l}\text { CHOs } \\
W S C\end{array}$ & 10,38 & 7,34 & 5,84 & 6,62 & 6,13 & 6,48 & 18,05 & NS \\
\hline $\begin{array}{l}\text { DIVMS } \\
\text { IVDDM }\end{array}$ & 52,87 & 60,83 & 59,24 & 61,57 & 58,93 & 60,14 & 2,70 & 0,0400 \\
\hline $\begin{array}{l}\mathrm{PT} \\
B C \\
\end{array}$ & 19,98 & 40,91 & 42,12 & 42,88 & 41,05 & 41,73 & 5,03 & NS \\
\hline
\end{tabular}

${ }^{1} \mathrm{MS}$ : matéria seca total (\%); PB: proteína bruta (\% MS); NIDA: nitrogênio insolúvel em detergente ácido (\% do N total); FDN: fibra em detergente neutro (\% MS); FDA: fibra em detergente ácido (\% MS); Lig: lignina (\% MS); Hemi: hemicelulose (\% MS); Cel: celulose (\% MS); Amido (\% MS); CHOs: carboidratos solúveis (\% MS); DIVMS: digestibilidade in vitro da matéria seca (\% MS); PT: poder tampão (meq./100 g MS de forragem); CV: coeficiente de variação (\%); Prob.: probabilidade estatística; NS: não significativo.

2 Linhas com letras sobrescritas diferentes diferem pelo teste Tukey $(5 \%)$.

1 DM: dry matter (\%); CP: crude protein (\% DM); ADIN: acid detergent insoluble nitrogen (\% of total N); NDF: neutral detergent fiber (\% DM); ADF: acid detergent fiber (\% DM); Lig: lignin (\% DM); Hemi: hemicellulose (\% DM); Cell: cellulose (\% DM); Starch (\% DM); WSC: water-soluble carbohydrate (\% DM); IVDDM: in vitro digestibility of the dry matter (\% DM); BC: buffering capacity (meq./100 g of DM); CV: coeficient of variation (\%); Prob: statistical probability; NS: not significant.

2 Rows with different letters differ by Tukey test (5\%).

R. Bras. Zootec., v.31, n.6, p.2373-2379, 2002 
A pequena magnitude de efeitos, obtidos no presente experimento, com o uso de inoculantes, concordam com os obtidos por Ely et al. (1981), que também não foram capazes de demonstrar efeitos desses produtos sobre a recuperação de nutrientes da silagem de sorgo. Reafirma-se, também, a citação de Harrison et al. (1994) de que os efeitos do uso de aditivos sobre a composição da silagem estão condicionados ao tipo de inoculante e à sua atividade biológica, à quantidade aplicada e ao tipo de forragem em teor de matéria seca e composição química.

Os dados de avaliação do perfil fermentativo das silagens submetidas aos quatro tratamentos encontram-se na Tabela 2. A adição dos inoculantes à silagem não alterou a concentração dos ácido acético, propiônico, butírico e lático, bem como o pH ou a concentração do nitrogênio amoniacal das silagens, embora os inoculantes tenham aumentado a concentração de etanol em 52,0\% (1,23 unidades percentuais), $55,5 \%$ ( 1,32 unidades percentuais) e 46,0 (1,09 unidades percentuais) para os produtos Sil-All, Silobac e Pioneer, respectivamente, em relação ao grupo controle. É possível que este efeito observado seja uma indicação de que os inoculantes tenham causado rápida acidificação da silagem, já que Chamberlain (1987) postulou que a rápida acidificação poderia favorecer o desenvolvimento de leveduras não sensíveis ao baixo $\mathrm{pH}$ e promover, portanto, a fermentação de açúcares residuais a etanol, dificultando a interpretação de resultados experimentais.

Os dados obtidos no presente experimento discordam dos obtidos por Meeske et al. (1983) e Sanderson (1993), os quais observaram aumento na produção de ácido lático e mais rápida redução no pH nas silagens de sorgo tratadas com inoculantes enzimomicrobianos ou microbianos, respectivamente, quando comparadas às silagens controles, mas concordam com os dados do experimento realizado por Ely et al. (1981), os quais não observaram efeitos dos inoculantes microbianos sobre o perfil fermentativo (concentração de ácidos orgânicos) e o pH da silagem desta forrageira.

Os dados de perdas de matéria seca por fermentação e de estabilidade aeróbia das silagens submetidas aos quatro tratamentos encontram-se na Tabela 3. O inoculante Pioneer diminuiu o tempo para alcançar a máxima temperatura, em relação ao grupo controle, embora nenhum efeito tenha sido observado sobre a temperatura máxima alcançada ou sobre a taxa de elevação da temperatura.

A diminuição do tempo para que a silagem atingisse a máxima temperatura, observada para o

Tabela 2 - Fermentação das silagens submetidas à aplicação de inoculantes

Table 2 - Fermentation pattern of inoculated silages

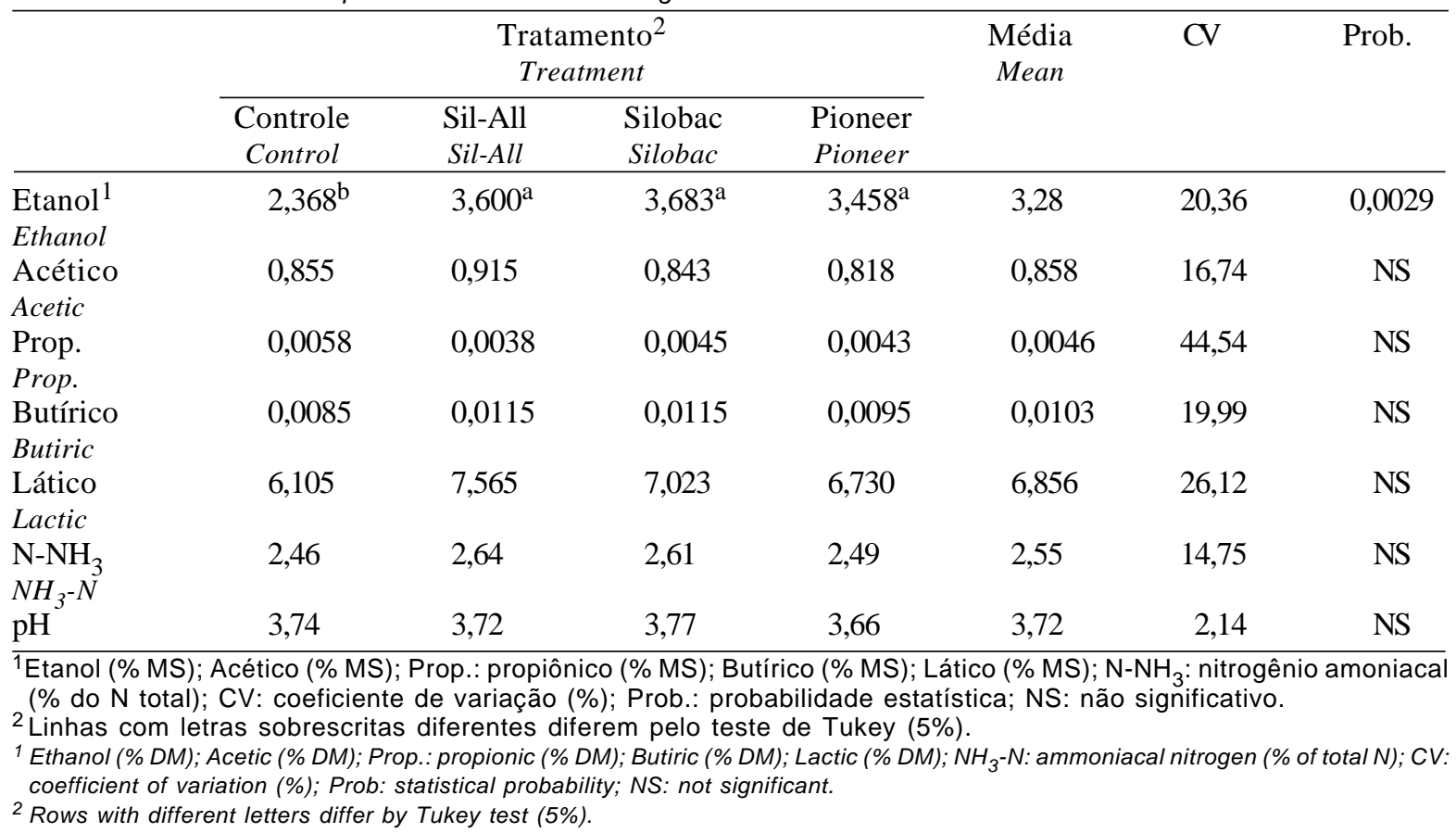

R. Bras. Zootec., v.31, n.6, p.2373-2379, 2002 
Tabela 3 - Perdas por fermentação e estabilidade aeróbia das silagens submetidas à aplicação de inoculantes

Table 3 - Fermentation losses and aerobic stability of inoculated silages

\begin{tabular}{|c|c|c|c|c|c|c|c|}
\hline & \multicolumn{4}{|c|}{$\begin{array}{c}\text { Tratamento }^{2} \\
\text { Treatment }\end{array}$} & \multirow[t]{2}{*}{$\begin{array}{l}\text { Média } \\
\text { Mean }\end{array}$} & \multirow[t]{2}{*}{$\mathrm{CV}$} & \multirow[t]{2}{*}{ Prob. } \\
\hline & $\begin{array}{c}\text { Controle } \\
\text { Control }\end{array}$ & $\begin{array}{l}\text { Sil-All } \\
\text { Sil-All } \\
\end{array}$ & $\begin{array}{l}\text { Silobac } \\
\text { Silobac }\end{array}$ & $\begin{array}{l}\text { Pioneer } \\
\text { Pioneer }\end{array}$ & & & \\
\hline $\begin{array}{l}\text { Perdas }{ }^{1} \\
\text { Losses }\end{array}$ & $-0,38^{b}$ & $8,63^{\mathrm{a}}$ & $8,73^{\mathrm{a}}$ & $14,14^{\mathrm{a}}$ & 7,78 & 75,60 & 0,0001 \\
\hline Tempo & $120,0^{\mathrm{a}}$ & $120,0^{\mathrm{a}}$ & $108,0^{\mathrm{ab}}$ & $96,0^{b}$ & 111,0 & 10,81 & 0,0009 \\
\hline $\begin{array}{l}\text { Period } \\
\text { Max. } \\
\text { Max. }\end{array}$ & 24,75 & 25,50 & 25,25 & 25,25 & 24,94 & 5,37 & NS \\
\hline $\begin{array}{l}\text { Taxa } \\
\text { Rate }\end{array}$ & 0,048 & 0,054 & 0,054 & 0,068 & 0,056 & 28,10 & NS \\
\hline
\end{tabular}

${ }^{1}$ Perdas: perdas de matéria seca (\%); Tempo: tempo decorrido para alcançar a máxima temperatura (horas); Max.: máxima temperatura alcançada $\left({ }^{\circ} \mathrm{C}\right)$; Taxa: taxa de elevação da temperatura $\left({ }^{\circ} \mathrm{C} / \mathrm{hora}\right)$; $\mathrm{CV}$ : coeficiente de variação $(\%)$; Prob.: probabilidade estatística; NS: não significativo.

${ }^{2}$ Linhas com letras sobrescritas diferentes diferem pelo teste Tukey (5\%).

${ }^{1}$ Losses: dry matter losses (\%); Period: period of time to reach maximum temperature (hours); Max.: maximum temperature $\left({ }^{\circ} \mathrm{C}\right)$; Rate: rate of increasing temperature ( ${ }^{\circ} \mathrm{C} /$ hour); $\mathrm{CV}$ : coefficient of variation (\%); Prob: statistical probability; NS: not significant.

${ }^{2}$ Rows with different letters differ by Tukey test (5\%).

inoculante Pioneer, parece concordar com a afirmação de Rust et al. (1989), de que o aumento das concentrações de ácido lático, resultado do aumento da fermentação do tipo homofermentativa, poderia resultar em silagens menos estáveis à deterioração aeróbia, quando da abertura do silo. No presente experimento, as concentrações de ácido lático não se apresentaram aumentadas no momento da abertura do silo com o processo de inoculação, embora verifica-se um aumento numérico nas concentrações desse ácido. Por outro lado, é possível que a rápida produção do ácido lático tenha favorecido a preservação de maior quantidade de carboidratos solúveis, que juntamente com obaixo $\mathrm{pH}$, tenham favorecido o desenvolvimento de leveduras, direcionando a produção de etanol. Maior número de leveduras estariam aptas a iniciar o processo de fermentação secundária, quando da abertura do silo. Esta condição poderia ser a responsável pela diminuição da estabilidade aeróbia das silagens inoculadas e não o ácido lático propriamente dito.

Os carboidratos solúveis, que a primeira instância, possuiriam concentrações aumentadas, logo seriam consumidos pelas leveduras favorecidas. A ausência de efeitos dos tratamentos sobre as concentrações de carboidratos solúveis residuais, obtidos no presente experimento, é compatível com a hipótese proposta nesta pesquisa.

\section{Conclusões}

Com base nos dados do presente experimento, não é possível recomendar a utilização de quaisquer dos inoculantes testados, na ensilagem da planta do sorgo, uma vez que nenhuma melhora foi observada sobre a composição química, perfil de fermentação ou estabilidade aeróbia dessa silagem.

\section{Agradecimento}

Aos funcionários Everson Lázaro e Gilmar Botteon, pelo cuidado com a cultura, e aos técnicos Ari de Castro, Gilson de Godoy e Simi Robassini, pela ajuda com as análises laboratoriais.

\section{Literatura Citada}

ASSOCIATION OF OFFICIAL ANALYTICAL CHEMISTS AOAC. Official methods of analysis. 10.ed. Washington, D.C., 1980. 1015p.

CHAMBERLAIN, D.G. The silage fermentation in relation to the utilization of nutrients in the rumen. Process Biochemistry, v.4, n.1, p.60-63, 1987.

CHEN, J.; STOKES, M.R.; WALLACE, C.R. Effects of enzymeinoculant systems on preservation and nutritive value of haycrop and corn silage. Journal of Dairy Science, v.77, n.1, p.501-512, 1994. 
CLEALE, R.M.; FIRKINS, J.L.; Van DE BEEK, F. et al. Effect of inoculation of whole plant corn forage with Pediococcus acidilactili and Lactobacillus xylosus on preservation of silage and heifer growth. Journal of Dairy Science, v.73, n.3, p.711-718, 1990.

CUMMINS, D.G. Relationships betweem tannin content and forage digestibility in sorghum. Agronomy Journal, v.63, n.2, p.500-502, 1971.

ELY, L.O.; SUDWEEKS, E.M.; MOON, N.J. Inoculation with Lactobacillus plantarun to alfafa, corn, sorghum, and wheat silages. Journal of Dairy Science, v.64, n.12, p.2378-2387, 1981.

ERWIN, E.S.; MARCO, G.J.; EMERY, E.M. Volatile fatty acid analyses of blood and rumen fluid by gas chromatography. Journal of Dairy Science, v.44, n.9, p.1768-1771, 1961.

FOLDAGER, J. Protein requeriment and non protein nitrogen for high producing cow in early lactation. East Lasing: Michigan State University, 1977. 167p. Tese (Doutorado em Ciência Animal) - Michigan State University, 1977.

HARRISON, J.H.; BLAUWIEKEL, R.; STOKES, M.R. Fermentation and utilization of grass silage. Journal of Dairy Science, v.77, n.10, p.3209-3235, 1994.

HENDERSON, N. Silage additives. Animal Feed Science and Technology, v.45, n.1, p.35-56, 1993.

JOHNSON, R.R.; BALWANI, T.L.; JOHNSON, L.J. et al. Corn plant maturity. II. Effect on in vitro cellulose digestibility and soluble carabohydrate content. Journal of Animal Science, v.25, n.3, p.617-623, 1966.

MEESKE, R.; ASHBELL, G.; WEINBERG, Z.G. et al. Ensiling forage sorghum at two stages of maturity with the addition of latic acid bacterial inoculants. Animal Feed Science and Technology, v.43, n.1, p.165-175, 1983.

PEREIRA, J.R.A.; ROSSI Jr., P. Manual prático de avaliação nutricional de alimentos. 1.ed. Piracicaba: Fundação de Estudos Agrários Luiz de Queiroz, 1995. 25p.

RUPPEL, K.A.; PITT, R.E.; CHASE, L.E. et al. Bunker silo management and its relationship to forage preservation on dairy farms. Journal of Dairy Science, v.78, n.1, p141-153, 1995.

RUST, S.R.; KIM, H.S.; ENDERS, G.L. Effects of microbial inoculant on fermentation characteristics and nutritive value of corn silage. Journal of Production Agriculture, v.2, n.1, p.235-241, 1989.
SANDERSON, M.A. Aerobic stability and in vitro fiber digestibility of microbially inoculated corn and sorghum silages. Journal of Animal Science, v.71, n.2, p505-514, 1993.

SAS INSTITUTE. SAS user's guide: statistics. 5.ed. Cary: 1985.

TILLEY, J.M.A.; TERRY, R.A. A two-stage technique for the in vitro digestion of forage crops. Journal of British Grassland Society, v.18, n.2, p.104-111, 1963.

TOSI, H. Conservação de forragem como consequência do manejo. In: SIMPÓSIO SOBRE MANEJO DE PASTAGENS, 1 ., 1973, Piracicaba. Anais... Piracicaba: Escola Superior de Agricultura Luiz de Queiroz, 1973. p.117-140.

Van SOEST, P.J. Development of a comprehensive system for analysis and its application to forage. Journal of Animal Science, v.26, n.1, p119-128, 1967.

Van SOEST, P.J.; ROBERTSON, J.B. Analysis of forages and fibrous foods. 1.ed. Ithaca: Cornell University, 1985. 202p.

WEBSTER, O.J. Effect of harvest dates on forage sorghum yields porcentage of dry-mater, protein and soluble solids. Agronomy Journal, v.55, n.7, p.1740-1747, 1962.

WHITTENBURRY, R.; McDONALD, P.; BRYAN JONES, D.G. A short review of some biochemical and microbiological aspects of ensilage. Journal of Science of Food and Agriculture, v.18, n.2, p.441-444, 1967.

ZAGO, C.P. Cultura de sorgo para a produção de silagem de alto valor nutritivo. In: SIMPÓSIO SOBRE NUTRIÇÃO DE BOVINOS, 4., 1991, Piracicaba. Anais... Piracicaba: Fundação de Estudos Agrários Luiz de Queiroz, 1991. p.169-213.

Recebido em: 21/01/02

Aceito em: 18/09/02 